\title{
Designing a quantitative safety checklist for the construction phase of ongoing projects in petrochemical plants
}

\author{
Zaranejad A, $\mathrm{PhD}^{1}$, Ahmadi O, $\mathrm{PhD}^{1^{*}}$, Yahyaei E, $\mathrm{MSc}^{2}$ \\ 1- PhD in Occupational Health Engineering, Dept. of Occupational Engineering, Faculty of Medical Sciences, Tarbiat \\ Modares University, Tehran, Iran. 2- MSc in Occupational Health Engineering, Dept. of Occupational Engineering, Faculty \\ of Medical Sciences, Tarbiat Modares University, Tehran, Iran.
}

\begin{abstract}
Received: May 2016, Accepted: November 2016

Background: One of the challenges in construction is the occurrence of numerous accidents. In this regard, risk assessment can play an important role in reducing accidents. The aim of this study was to prepare comprehensive and quantitative checklists to determine the potential hazards in the construction phase.

Materials and Methods: The present descriptive and analytical study was carried out on petrochemical projects in the south of Iran in 2014. After the inspection of more than 50 construction projects, two types of technical and managerial checklists were designed. The managerial and technical checklists were designed with seven and 32 major subjects, respectively. Finally prepared checklist and ET\&BA method were compared in term of their risk identification capability.

Results: The checklist and ET\&BA methods, respectively, identified 300, 75, 125, and 48, and 107, 25,12 , and 0 risks related to hardware, design, mismanagement, and human error.

Conclusions: The checklist method can identify and assess human errors, while the ET\&BA method cannot. Moreover, this method was more efficient than the ET\&BA technique in identification and assessment of hardware-related, design-related, and managerial risks. Moreover, the duration and cost of implementation of checklist method were significantly lower than ET\&BA method. This technique can be introduced as a quantitative risk assessment method in construction phases of projects and its weaknesses can be improved by future studies.
\end{abstract}

Keywords: Accidents, Checklist, Construction, Risk Assessment.

\section{Introduction}

The construction phase of a project is one of the intermediate phases of the development of its plan and design, and supply and commissioning services. The initial phase of a new project is important because decisions made in the early stages of the project affect its final costs. In this regard, risk management can play an important role in controlling and reducing the related risks (1). The occurrence rate of work accidents in construction sectors is always higher than other sectors $(2,3)$. The construction sector employs about $7 \%$ of the world's employees, but is also responsible for $30-40 \%$ of work-related fatalities (4). The
Iranian construction industry encompasses only $29 \%$ of industrial workers; however, it causes approximately $40 \%$ of workplace accidents (5). The exposure of workers to potentially severe hazards is an important concern in the construction industry (6). For the same reason and due to the recurrence of accidents, a strong need is sensed for the development of an appropriate strategy to reduce the rate of accidents in these projects. To prevent incidents, safety experts must recognize, assess, and reduce or control

\footnotetext{
" Corresponding author: Omran Ahmadi, Dept. of Occupational Engineering, Faculty of Medical Sciences, Tarbiat Modares University, Tehran, Iran. E-mail: o.ahmadi@modares.ac.ir
} 
potentially small, large, visible, and invisible hazards using risk assessment and management techniques. The importance of risk assessment is to facilitate decision-making regarding the selection of good solutions and to convince managers to spend resources for safety solution (7). Without a structured identification system, hazards can be overlooked, thus, resulting in incomplete riskevaluations and potential losses (8). The use of a checklist is one of the risk assessment methods. Checklist analysis is a systematic evaluation with a pre-established content which consists of questions about any area of installation safety concern and is the simplest method used for hazard identification (9). Checklists have many objectives, including memory recall, and standardization and regulation of processes or methodologies, which provide a framework for evaluations or as a diagnostic tool. Several studies have been carried out on the designing of checklists (1015). Checklists should be prepared in the form of small sentences and should be designed with a complete link to the goal. The most important advantages and shortcomings of checklists are mentioned in table 1 (17).

Table 1: The most important advantages and disadvantages of checklists

\begin{tabular}{|c|c|}
\hline Advantages & Disadvantages \\
\hline $\begin{array}{l}\text { The checklist is the simplest technique for } \\
\text { recognition of hazards. }\end{array}$ & $\begin{array}{l}\text { It has the least possible compatibility with the } \\
\text { adopted standards. }\end{array}$ \\
\hline though designing a checklist requires accurate & If the checklist is studied independently, it may \\
\hline $\begin{array}{l}\text { information and knowledge, its completion does not } \\
\text { require skilled and specialized personnel. }\end{array}$ & $\begin{array}{l}\text { overlook the potential hazards that have not been } \\
\text { identified due to some eliminated subjects. }\end{array}$ \\
\hline $\begin{array}{l}\text { It is applicable in all stages of the implementation } \\
\text { of the project. }\end{array}$ & $\begin{array}{c}\text { It use brainstorming and it is not the product of } \\
\text { collective wisdom. }\end{array}$ \\
\hline It is a swift and easy method for studying hazards. & $\begin{array}{l}\text { A checklist provides simple documents about the } \\
\text { condition and status of a particular subject. }\end{array}$ \\
\hline $\begin{array}{l}\text { The items can go into detail based on the need and } \\
\text { the necessity. }\end{array}$ & A checklist limits the imagination of the individual. \\
\hline $\begin{array}{l}\text { The application of the instructions and the } \\
\text { philosophy of utilization can take place in the form } \\
\text { of questions within the framework of this method. }\end{array}$ & $\begin{array}{l}\text { Checklists are only designed based on the abilities } \\
\text { and experiences of those who prepared them. }\end{array}$ \\
\hline $\begin{array}{l}\text { Although the designing of a checklist requires } \\
\text { accurate information and knowledge, one can reach } \\
\text { effective results by preparation of written } \\
\text { instructions and a minimum amount of training. }\end{array}$ & $\begin{array}{c}\text { The items should be prepared by very experienced } \\
\text { individual and/or individuals who have knowledge } \\
\text { of the standards and are completely skilled in } \\
\text { designing, and utilization. }\end{array}$ \\
\hline $\begin{array}{l}\text { Checklists can be considered as a very conducive } \\
\text { method in the hazard identification phase. }\end{array}$ & $\begin{array}{c}\text { A checklist that has been prepared by people other } \\
\text { than experts, neglects the sensitive and critical } \\
\text { subjects. }\end{array}$ \\
\hline $\begin{array}{l}\text { The results of this method can be used in other } \\
\text { safety assessment techniques. }\end{array}$ & $\begin{array}{l}\text { A checklist can only focus on one particular subject } \\
\text { at a particular time, and therefore, hazards resulting } \\
\text { from the relations and connection of the } \\
\text { interactions, which exist between processes, cannot } \\
\text { be identified by it. }\end{array}$ \\
\hline
\end{tabular}

Based on the classification of checklist items, checklists are divided into three major groups; the first group is yes/no and positive/negative, the second group is weak/relatively medium/good/excellent, and the third group is the scoring method. The first group is a qualitative method, and it is not comprehensive and precise, since they do not specify the level of appropriateness and inappropriateness of the safety. The second group is also a qualitative method that can specify the quality, and the level of appropriateness and inappropriateness of the safety; however the safety status of the organization cannot be judged through this method. Hence, it is not precise and comprehensive. In the third group, the table of scoring assessment is taken into consideration 
based on the importance of the subject from a safety perspective (18). In this method, the checklist subjects receive an independent score based on their importance in terms of safety. Hence, it is a suitable method for the assessment of the safety of an organization. Evidently, the best checklist assessment method is the scoring technique. Nevertheless, it is better to use this method concurrently with the first and second methods, since the level of appropriateness of each subject is unclear in relation to itself in this method. In addition, the Health and Safety Executive (HSE; Liverpool, UK) recommends the use of a combination of scoring method and weak/relative medium/good/excellent method. This institute has considered the same rate for each of the checklist subjects, which does not seem to be logical with regards to the nature of different industries and their related hazards. On the other hand, this technique has not been taken into consideration since one of the fundamental principles in designing a checklist is to consider a "yes/no" response in it. In the present study, a hybrid scoring and yes/no techniques were incorporated. This method has also been proposed by the U.S. Safety Department (19).

One of the major studies conducted in Iran in this regard is the thesis of Parvin Shafiee Moqadam (March 2000). In this project, 44 important safety, hygiene, and environment related topics were considered in terms of their educational level, equipment, policy, methods, rules, conducts, documents, and etc. Different checklists were drafted for safety assessment and the checklists were scored for the quantitative and qualitative assessment. The results showed the safety score and the safety percentage were, respectively, 0.5 and $38 \%$. This means the safety conditions in the workshop was at an average level and it is necessary to draft a fundamental and comprehensive plan to promote the safety conditions.

The aim of the present study was to design comprehensive and quantitative checklists to determine potential hazards in the construction phase of ongoing projects.

\section{Material and Methods}

The present descriptive and analytical study was carried out on petrochemical projects in the south of Iran in 2014. First, two types of technical and managerial checklists were designed after inspection and field study of more than 50 construction projects.

The managerial checklists were designed with seven major criteria and in 32 important and major subjects for technical inspection and qualitative control.

Evidently, the topic of safety should be included in all organizational structures, goals, policies, ideals, and other processes necessary for continuation of the company's activities. In other words, the company should pay attention to safety promotion to an extent that every individual realizes that the company considers safety topics a serious issue. Therefore, the managerial checklist should be designed with the seven major subjects of managerial commitments and requirements, identification and control of hazards, professional rules and instructions, education, communications, reporting and coverage of the accidents and incidents, and assessment within the site. In this checklist, the three methods including interview with the operational personnel and managers, observance of the site of installations and personnel performance conditions and review of documentation were incorporated in order to answer the questions. Moreover, related documents were studied and a particular score was considered for each of them (the scoring method). In addition, the yes/no method was used to judge the studied case. In the technical checklist, after interviewing the construction engineers and studying related technical documents, 32 important and major subjects were selected in the unit construction operations and were assessed by a combination of the scoring and yes/no methods (20). These subjects include scaffoldings, excavation, protection against 
fall, ropes, machinery barrier, tools and equipment, welding, electrical hazards, equipment and personal protective clothes, concrete constructions, destruction, protection against and prevention of fire, lifters, traffic control, limited closed environment, explosion, erection of steel structures, cranes, vehicle, guard rails, open areas of the wall and the floor, stairs and stair railing, construction of concrete block of walls, fixed ladders, mobile ladders, workshop discipline, methods to stop the locking and labeling operations, sanding machines, lathe and other abrasive machines, hazard communication, personnel platforms, asbestos, and contact with silica and radiation. The importance of the studied subjects was determined based on the study of accidents in the construction phase of the industries by the experts committee that was composed of engineers and qualified specialists and consultants in the fields of civil, mechanical, chemical, and safety engineering. All of the experts had at least 15 years job experience. The maximum score (acceptable status in the safety viewpoint) was considered for every single question in each checklist. After studying the considered subject, it was scored. If the maximum score was equal to or more than $85 \%$, a positive response was given otherwise negative. It was classified as a contract. After calculation of the ratio of total scores to the maximum possible scores, the appropriateness of subjects were studied based on four criteria to judge the checklist in a general way. For this reason, the decisionmaking process provided by the MIL-STD882C (Military-Standard-882C) standard was used (20). Moreover, the safety score of the studied system was calculated according to the following equation (1) to judge the studied system (21).

$$
\mathrm{SS}=\frac{\sum_{i=1}^{n} A \times B}{\sum_{i=1}^{n} A}
$$

Table 2: Standard indices for judging a checklist

\begin{tabular}{lc}
\hline \multicolumn{1}{c}{ Hazard risk index } & $\begin{array}{c}\text { Decision-making standard (based on the ratio of the gained score to } \\
\text { the maximum score in percentage, } \mathbf{X})\end{array}$ \\
\hline Acceptable without revision & $\mathrm{X}>85$ \\
\hline Acceptable with revision & $\mathrm{X}=50-85$ \\
\hline Inappropriate & $\mathrm{X}=41-49$ \\
\hline Unacceptable & $\mathrm{X}<40$ \\
\hline
\end{tabular}

In this equation, $\mathrm{A}$ is the level of priority of the stated subjects in relation to each other (Table 3), B is the gained score in each subject, and SS is the safety score. Following the calculation of the safety score, a comment was made on the safety status of the site via applying the standard of judgment presented in table 2. By establishing the experts committee comprised of experts in all fields, the checklist was transformed from a product of individual thought to the product of collective wisdom after the multilateral study of the subjects from different viewpoints. Therefore, the role of personal preference would fall to the minimum possible level (21). The priority of different subjects in the checklist was determined by the experts (their selection was previously explained). To compare the potentials of this method with other methods of risk assessment, different techniques were studied by a committee comprised of civil, mechanical, electrical, and chemical, and safety engineers. Finally, the experts committee presented the energy trace and barrier analysis (ET\&BA) method as the only rival to the checklist technique for identification of hazards and their assessment in construction projects. Although different risk assessment methods are used for projects under construction, according to the experts' proposal, ET\&BA 
method is more efficient than other methods. Bagher Mortazavi et al., in their study in 2007, stated that ET\&BA method is a good method for risk assessment in construction projects (22). Jamshidi et al. in 2013 pointed out that methods such as ET \& BA can evaluate the risks in various industries especially in construction industries (23). Therefore, the results of this study were compared with those of ET\&BA method. The rates and levels of risks at one of the construction phases of petrochemical sites, where many incidents had occurred in the previous year, was assessed by application of both designed checklists and ET\&BA method. The ET\&BA is a systembased analysis developed to assist the identification of hazards by focusing on the presence of energy and the barriers that may influence energy control in the system (24).
ET\&BA is implemented in the following stages:

- Identification of the energy types

- Determination of barriers in the energy pathways

- Determination of vulnerable targets including personnel and equipment

- Determination of the risk levels of hazards and effectiveness of control methods

- Definition of the controls to reduce the risk

- Re-determination of hazards' risk levels (7)

\section{Results}

In present study 39 completed checklists was designed. Priority of different subjects in the checklist determined by the experts is presented in table 3 .

Table 3: Priority of the different sections presented in the checklist method

\begin{tabular}{|c|c|c|c|c|c|}
\hline Topic & $\begin{array}{c}\text { Priority } \\
\text { ranking }(\mathbf{A})\end{array}$ & Topic & $\begin{array}{c}\text { Priority } \\
\text { ranking }(\mathbf{A})\end{array}$ & Topic & $\begin{array}{c}\text { Priority } \\
\text { ranking } \\
\text { (A) }\end{array}$ \\
\hline $\begin{array}{l}\text { Management } \\
\text { commitments } \\
\text { and } \\
\text { requirements }\end{array}$ & 1 & Confined spaces & 14 & Fixed ladders & 27 \\
\hline $\begin{array}{c}\text { Hazards } \\
\text { identification } \\
\text { and control }\end{array}$ & 2 & $\begin{array}{c}\text { Personal } \\
\text { protection } \\
\text { equipment } \\
(\mathrm{PPE}) \\
\end{array}$ & 15 & Mobile ladders & 28 \\
\hline $\begin{array}{l}\text { Working rules } \\
\text { and instructions }\end{array}$ & 3 & Open areas & 16 & Radiation & 29 \\
\hline Education & 4 & $\begin{array}{l}\text { Workshop } \\
\text { discipline }\end{array}$ & 17 & Exposure to $\mathrm{SiO}_{2}$ & 30 \\
\hline Communications & 5 & $\begin{array}{l}\text { Sanding and } \\
\text { cutting } \\
\text { machines and } \\
\text { other abrasive } \\
\text { machines }\end{array}$ & 18 & Asbestos & 31 \\
\hline $\begin{array}{l}\text { Accidents and } \\
\text { events report }\end{array}$ & 6 & Traffic control & 19 & Platforms & 32 \\
\hline $\begin{array}{l}\text { Within site } \\
\text { control }\end{array}$ & 7 & $\begin{array}{c}\text { Erection of steel } \\
\text { structures }\end{array}$ & 20 & $\begin{array}{c}\text { Hazard } \\
\text { communication }\end{array}$ & 33 \\
\hline Scaffolding & 8 & Cranes & 21 & Tag out / lag out & 34 \\
\hline Excavation & 9 & Transportations & 22 & Explosion & 35 \\
\hline $\begin{array}{c}\text { Working at } \\
\text { height }\end{array}$ & 10 & $\begin{array}{l}\text { Stairs and their } \\
\text { railings }\end{array}$ & 23 & Ropes & 36 \\
\hline $\begin{array}{c}\text { Electrical } \\
\text { hazards }\end{array}$ & 11 & $\begin{array}{l}\text { Construction of } \\
\text { walls }\end{array}$ & 24 & $\begin{array}{c}\text { Concrete } \\
\text { Constructions } \\
\end{array}$ & 37 \\
\hline Welding & 12 & Guard rails & 25 & \multirow{2}{*}{ Destruction } & \multirow{2}{*}{38} \\
\hline Fire fighting & 13 & Aerial lifters & 26 & & \\
\hline
\end{tabular}


Table 4: Comparison of the results obtained, the number of sessions held, and the time spent in the two designed checklists and ET\&BA methods

\begin{tabular}{ccc}
\hline \multirow{2}{*}{ DETAIL } & \multicolumn{2}{c}{ Method } \\
\cline { 2 - 3 } & Checklists & ET\&BA \\
\hline Number of experts in the team & 3 & 6 \\
\hline Number of meetings held & 5 & 15 \\
\hline Time spent (person/hour) & 30 & 270 \\
\hline Identified risks & 548 & 144 \\
\hline Unacceptable risks & 500 & 141 \\
\hline Proposals for reformation & 505 & 201 \\
\hline
\end{tabular}

The results of the comparison of the designed checklists and ET\&BA method are presented in tables 4-6 and figures 1-3. The results of this comparison showed that the quantity of 548 and 144 risks were identified using the checklists and ET\&BA method, respectively. ET\&BA method did not have the ability to identify human errors, while the checklist method identified 48 human errors.

Based on the results, it was observed that the checklist method only requires $\frac{1}{9}$ and $\frac{1}{10}$ of the time and money spent in the ET\&BA method, respectively. Using the designed checklist for risk assessment increased the number of risks identified; the identified risks and presented proposals for controlling the identified risks represented an increase of $400 \%$ and $250 \%$, respectively, compared to ET\&BA method. The checklist method could identify and assess human errors (48 of the identified risks were related to human error), but the ET\&BA method lacked this advantage (did not identify any human errors). Checklist and ET\&BA methods identified 300 and 107 hardwarerelated risks, respectively. In other words, checklist method was three times stronger than ET\&BA method in identification and assessment of hardware-related risks. Checklist and ET\&BA methods identified 25 and 75 design-related risks, respectively. In other words, checklist method was three times stronger than ET\&BA method in identification and assessment of design-related risks. Moreover, checklist method is 10.5 times efficient than ET\&BA method in identification and assessment of managementrelated risks; checklist and ET\&BA methods identified 125 and 12 management-related risks, respectively. The majority of risks that were identified by ET\&BA and checklist methods were related to hardware $(75 \%$ and $53 \%$ of total identified risks, respectively). This indicates that ET\&BA method focuses more on the risks associated with hardware and less on those related to design, management, and human error.

Table 5: Comparison of the designed checklists and ET\&BA methods from the viewpoint of the type and Number of risks identified

\begin{tabular}{ccc}
\hline Risk type & ET\&BA & Checklists \\
\hline Hardware & 107 & 300 \\
\hline Design & 25 & 75 \\
\hline Mismanagement & 12 & 125 \\
\hline Human error & 0 & 48 \\
\hline Total & 144 & 548 \\
\hline
\end{tabular}


Table 6: Comparison of the capabilities of the designed checklists with ET\&BA method

\begin{tabular}{|c|c|c|}
\hline Checklist & ET\&BA & Detail \\
\hline It has & It has not & $\begin{array}{l}\text { The ability to judge each of the studied } \\
\text { disciplines in a quantitative manner }\end{array}$ \\
\hline $\begin{array}{c}\text { Ineffective safety measures } \\
\text { Defective protective equipment } \\
\text { Unsafe machinery and equipment } \\
\text { Unsafe and defective equipment, } \\
\text { tools, and machinery }\end{array}$ & It has not & $\begin{array}{c}\text { The ability to judge the studied site } \\
\text { qualitatively }\end{array}$ \\
\hline It has & It has not & $\begin{array}{l}\text { The ability to judge deviation from the } \\
\text { standard }\end{array}$ \\
\hline
\end{tabular}

\section{Discussion}

In this study, a new risk assessment method was proposed and utilized as a one case study in the construction phase of petrochemical sites. To compare the potentials of this method with other methods of risk assessment, the experts committee presented the ET\&BA method as the only rival to the checklist technique for identification of hazards and their assessment in construction projects. Many researchers believe that the ET\&BA method of hazard identification and risk assessment is efficient and powerful $(22,23)$.

The results and findings of this study showed that although the designing of the proposed method requires comprehensive information, its use does not require skilled personnel. This is a great benefit because many construction workers that are seasonal workers and indigenous, do not have enough literacy and are unfamiliar with the hazards of working in phases of construction.

On the other hand, this method is used at all stages of a project. It is a very easy and quick method of hazard identification and risk assessment. This method can also enter the technical and operational details that other risk assessment methods are not capable of.

This method can be very useful guidance for the documentation of work instructions and designing of educational programs. In compared with other methods, checklist is powerful in identification of unsafe behavior and human errors.
A limitation of the checklists method is that it can only focus on one particular subject at a particular time, and therefore, hazards resulting from the relations and connection of the reactions, which exist between processes and methods, cannot be identified by it.

The designed checklist method which considers different types of hardware-related, managerial, design-related, and human error risks was an efficient method in analyzing such systems by spending the minimum possible time and money in compared with ET\&BA method. It may not only be a rival to the ET\&BA technique, but can also replace the ET\&BA method as a more efficient method. As mentioned by Marhavilas et al., another advantage of checklists may be their applicability to any activity or system, generally. Furthermore, this method ensures that organizations comply with standard practices if it is performed by an individual that has been trained to understand the checklist items. In addition to its simple application, this technique can answer more complicated risk-related questions only if some degree of quantification is added with a relative ranking approach for equipment and human factors. One weakness of this method was its qualitative approach (16).

In the present study, this kind of weakness was resolved by quantifying the checklist. An advantage of the checklist method was its flexibility for each organization with regard to the nature of the work; it was applicable in all stages of the project implementation. Tam et 
al. noted that different companies tend to have different scales of safety management systems because of inadequate data or imprecise information available on construction sites (25). However, risk analysis and hazard assessment is at the core of safety practices in any case. Thus, the checklist method was the best option for risk assessment in these cases. The limitation of this research was lack of a regular, developed, and standard system for construction projects' management that resulted in the wasting of much time and energy by the research team.

\section{Conclusion}

The designed checklists method was an efficient technique in analysis of systems and considered different risks related to hardware, management, and design, and human errors in the least amount of time and with the least costs. Hence, it can be a potential alternative to other risk assessment methods. Therefore, this technique can be introduced as one of the strongest risk assessment methods in construction phases of projects.

\section{Acknowledgments}

The authors would like to thank the experts who participated in this project and assisted in its performance.

Conflict of interest: None declared

\section{References}

1. Haslam RA, Hide SA, Gibb AG, Gyi DE, Pavitt T, Atkinson S, et al. Contributing factors in construction accidents. Appl Ergon 2005; 36(4):401-15.

2. Yng Ling FY, Liu M, Woo YC. Construction fatalities in Singapore. International Journal of Project Management 2009; 27(7):717-26.

3. Dong XS, Choi SD, Borchardt JG, Wang X, Largay JA. Fatal falls from roofs among U.S. construction workers. J Safety Res 2013; 44(1):17-24.

4. Sunindijo RY, Zou PXW. How project manager's skills may influence the development of safety climate in construction projects. International Journal of Project
Organisation and Management 2012; 4(3):286301.

5. Iran. Department of Labour Inspection, Construction Accident Report in 2011. Tehran: Labour Inspection Department of the Ministry of Labour and Social Affairs; 2011.

6. Chi N-W, Lin K-Y, El-Gohary N, Hsieh S-H. Evaluating the strength of text classification categories for supporting construction field inspection. Automation in Construction 2016; 64(4):78-88.

7. Arghami S, Abbasi S, Bakhtom Sh, Ziaei M. Comparing of HAZOP and ETBA techniques in safety risk assessment at gasoline refinery industry. African Journal of Basic \& Applied Sciences 2014; 6(1):1-5.

8. Dunjó J, Fthenakis V, Vílchez JA, Arnaldos J. Hazard and operability (HAZOP) analysis. A literature review. J Hazard Mater 2010; 173(13):19-32.

9. Marhavilas PK, Koulouriotis DE. A riskestimation methodological framework using quantitative assessment techniques and real accidents' data: Application in an aluminum extrusion industry. J Loss Prev Process Ind 2008; 21(6):596-603.

10. Jou Y-T, Lin CJ, Yenn T-C, Yang Ch-W, Yang L-Ch, Tsai R-Ch. The implementation of a human factors engineering checklist for human-system interfaces upgrade in nuclear power plants. Saf Sci 2009; 47(7):1016-25.

11. Dennerlein JT, Ronk CJ, Perry MJ. Portable ladder assessment tool development and validation-quantifying best practices in the field. Saf Sci 2009; 47(5):636-9.

12. Piniella F, Fernández-Engo MA. Towards system for the management of safety on board artisanal fishing vessels: Proposal for checklists and their application. Saf Sci 2009; 47(2):265-76.

13. Parker D, Lawrie M, Hudson P. A framework for understanding the development of organisational safety culture. Saf Sci 2006; 44(6):551-62.

14. Wu HCh, Chen HCh, Chen T. Effects of ergonomics-based wafer-handling training on reduction in musculoskeletal disorders among wafer handlers. Int $\mathbf{J}$ Ind Ergon 2009; 39(1):127-32.

15. True BA, Cochrane CC, Sleutel MR, Newcomb P, Tullar PE, Sammons Jr JH. Developing and testing a vaginal delivery safety checklist. J Obstet Gynecol Neonatal Nurs 2016; 45(2):239-48.

16. Marhavilas PK, Koulouriotis D, Gemeni V. Risk analysis and assessment methodologies in the work sites: On a review, classification and comparative study of the scientific literature of 
the period 2000-2009. J Loss Prev Process Ind 2011;24(5):477-523.

17. Roland HE, Moriarty B. System safety engineering and management. $2^{\text {nd }}$ ed. New York, United States: John Wiley \& Sons, Inc.; 1990.

18. Vincoli JW. Basic guide to system safety. $2^{\text {nd }}$ ed. New York, United States: John Wiley \& Sons, Inc.; 2006.

19. Laing PM, Schmidt PhE. Accident prevention manual for business and industry: engineering and technology. $1^{\text {st }}$ ed. Washington D.C, United States: National Safety Council; 1992.

20. Allen E, Iano J. Fundamentals of building construction: materials and methods. $5^{\text {th }}$ ed. New York, United States: John Wiley \& Sons, Inc.; 2008.

21. Department of Defense. Military Standard System Safety Program Requirements. Departments and Agencies of the Department of Defense, United States of America; 1993 Jan. Report No.: MIL-STD-882C.
22. Zarranezhad A, Mortazavi SB, Asilian Mahabadi H, Khavanin A. Identification and safety assessment of the hazardous zones (unwanted energy flows) in an construction project at the national petrochemical company by application of ET\& BA method. J Appl Sci 2007; 7(19):2769-75.

23. Santos-Reyes J, Alvarado-Corona R, OlmosPeña S. Learning from Tabasco's floods by applying MORT. Saf Sci 2010; 48(10):135160.

24. Jamshidi A, Yazdani Chamzini A, Haji Yakhchali S, Khaleghi S. Developing a new fuzzy inference system for pipeline risk assessment. J Loss Prev Process Ind 2013; 26(1):197-208.

25. Tam CM, Tong TKL, Chiu GCW, Fung IWH. Non-structural fuzzy decision support system for evaluation of construction safety management system. International Journal of Project Management 2002; 20(4):303-13. 